\title{
Optimal Location of PV based Distributed Generation in Pool based Electricity Market using Mixed Integer Non Linear Programming
}

\author{
Manish Kumar ${ }^{1}$, Ashwani Kumar ${ }^{2}$ and K.S Sandhu ${ }^{3}$ \\ ${ }^{1}$ National institute of Technology, kurukshetra-131961, India \\ ${ }^{2,3}$ National institute of Technology, kurukshetra-131961, India \\ ${ }^{1}$ Khanagwal.manish@gmail.com, \\ 2ashwa_ks@yahoo.co.in, ${ }^{3}$ kjssandhu@rediffmail.com
}

\begin{abstract}
Renewable sources integration is gaining importance in electrical utilities all over the world. The liberization of power sector in competitive regime, the share of renewable energy sources is increasing and it is essential to carry out the impact of dean energy on the system performance In this paper, analysis has been carrled out with the PV-based distribution generation in the power system network. A Mixed Vtateger Nonlinear Programming (MINLP) approach has been utilized for determining ptimal location and number of distributed generators considering minimization of fuel cost of conventional and solar PV power. The pattern of nodal reat and reactive power prices have been obtained with and without PV integration. The results are also obtained for, loss reduction, fuel cost saving and voltage profile. The impact of different load models as $P Q$ load and Zip load model has been studled. The proposed MINLP based optimization approach has been applied for LEEE2 4 bus reliability test system.
\end{abstract}

Keywords: Mixed Integer Nonlinear Programming (MINLP) approach, Nodal price, optimal location, solar PVBased Distributed generator

\section{Introduction}

The liberalization of the electrity markets all over the world in the last two decades leads competition in the electricity sector. The utilities all over the world due to environmental concerned polices and pressure from the financial institutions have shifted their paradigm for optimal utilization of the existing sources and integration of renewable energy sources in the system [1] So, the electricity supply industries targeted to optimal, secure and economically power generation. The energy demand is increasing drastically and it is important for the electricity supply industry to plan and develop alternate generation system. The renewable energy resources and distributed generation is a feasible alternative for reducing networks losses and congestion especially during peak hours, which also improves system reliability, voltage profile and saving the fuel cost. In completive markets, distributed generation plays an important role due to their economic viability and small size. A competitive market mechanism for DG in a pool based system was proposed in [2]. Many authors defined distributed generation based on their size, technologies, location, power delivery area and operational constraints with their economical and operational benefits [3-5]. The DG technologies comprise small gas turbines, micro-turbines, fuel cells, wind and solar energy.

With the increase in distributed energy sources in the power system network, it has become essential to study their impact on the system performance. The planning of the system in the presence of DGs require several factors to consider with the number and the capacity of units, location in the network, and impact of DG on the system operational 
characteristics such as system losses, voltage profile, stability and reliability issues [6-8]. A framework for implementing optimal DG capacity investment as an attractive option in distribution system planning in deregulated electricity market is proposed in [9].

Many researchers proposed algorithms and methods for optimal location and sizing of the distributed generation plants. The various techniques of intelligent control methods , particle swarm optimization(PSO), genetic algorithm and Tabu search, Noval approach, Ant Colony Optimization, Evolutionary Programming , Mixed integer programming , and some other heuristic approaches, of course other studies have also been presented [1023]. An analytical method for optimal DG location is proposed in [Gautam]. Authors proposed in [24] decision made by system planner (DMSP) approach for allocation of DGs in the system and optimization method consists of minimizing loss and cost. Authors in references $[25,26]$ proposed an artificial intelligent method used for DG allocation. Teaching-learning based optimization (TLBO) algorithm for economic analysis of unit commitment with integration of distributed energy resources is proposed in [27, 28]. A mixed integer non-linear programming (MINLP) approach has been proposed to determining optimal location and number of distributed generator in pool electricity market for minimization of fuel cost and transmission losses [29, 30]. Most of the authors have considered wind power sources along with fossil fuel based sources with fuel cost minimization for DG allocation, loss minimization. Solar PV system along with its cost function needs to be modeled in the optimization problem formulation along with conventional generators for analyzing the impact of solar RV system on the system performance.

In this paper, analysis has been carried out with solaCbased PV system as a DG. The solar PV power has been obtaine based on $\beta$ function. The solar PV cost function has been incorporated along with cost of conventional generators. A mixed integer nonlinear programming (MINL) approach has been utilized for determining optimal location and number of distributed generators. The pattern of the nodal prices has been obtained without and vith solar PV DG considering its cost function. The voltage and loss profile has a1so been obtained without and with solar PV DG for comparison The impact of realistic ZIP load has also been considered along with constant R load model The proposed MINLP based optimization approach has been applied for IEEF 24 bus reliability test system.

\section{PV-based DG Power and Cost Function}

PV module output power is depend upon the main three factors: (i) solar irradiance, (ii) ambient temperature or the site and (iii) characteristics of module itself. In this analysis we use two type or PV module [31]. PV-based DG system required rating is MW but the PV module rating is very small in W. Thus PV panel consisting of 2600 module for achieved this rating. The output powers of each PV plant (PV1 plant, PV2 plant) are obtained 24 hours based on three years of the collected data and the 24 hours output power of the each PV plant. But we have use the average power output of day in the every PV plant. The average value of active and reactive power generation of each PV plant, PV 1 lant active power is $0.2162 \mathrm{MW}$ and reactive power is $0.0308 \mathrm{MW}$, and PV2 plant active power is $0.3348 \mathrm{MW}$ and $0.047 \mathrm{MW}$ are the reactive power of the PV plant.

$$
P(c)=a_{P V}+b_{P V} P_{P V}+c_{P V} P_{P V}^{2}
$$

Where $\mathrm{P}(\mathrm{c})$ is the cost function of PV-based DG and $\mathrm{P}_{\mathrm{PV}}$ is the generated power in MW. The $a_{\mathrm{PV}}, \mathrm{b}_{\mathrm{PV}}, \mathrm{c}_{\mathrm{PV}}$ are cost coefficient of PV plants in $\$, \$ / \mathrm{MWh}, \$ / \mathrm{MWh}^{2}$. In PV1 plants cost function $\left(\mathrm{a}_{\mathrm{PV}}=4.45 \$, \mathrm{~b}_{\mathrm{PV}}=29.30 \$ / \mathrm{MWh}, \mathrm{c}_{\mathrm{PV}}=0.0055 \$ / \mathrm{MWh}^{2}\right)$ and $\mathrm{PV} 2$ plant cost function $\left(\mathrm{a}_{\mathrm{PV}}=4.46 \$, \mathrm{~b}_{\mathrm{PV}}=29.58 \$ / \mathrm{MWh}, \mathrm{c}_{\mathrm{PV}}=0.0055 \$ / \mathrm{MWh}^{2}\right)$ are refer to [32]. 


\section{General OPF Formulation}

A general mathematical model minimizing fuel cost of conventional generators and the cost function of solar PV based power source has been considered subject to satisfying the equality and inequality constraints is:

Min $F\left(h, g, \xi^{\text {int }}\right)$

Subject to equality and inequality constraints defined as

$$
\begin{aligned}
& x\left(h, g, \xi^{\mathrm{int}}\right)=0 \\
& u\left(h, g, \xi^{\mathrm{int}}\right) \leq 0
\end{aligned}
$$

Where,

$h$ is state vector of variables $V, \delta$;

$g$ are the control parameters, $P_{g k}, Q_{g k}, P_{P V k}, Q_{P V k}$;

$\xi^{\text {int }}$ is an integer variable with values $\{0,1\}$. The zero value means without and one value mean with distributed generator in the network.

Objective function $\mathrm{F}$ with only cost function of conventional generators is

Min $F\left(h, g, \xi^{\mathrm{int}}\right)=\left\{\sum_{k \in N_{g}}\left(a_{g k}+b_{g k} P_{g k}+c_{g k} P_{g k}^{2}\right)\right\}$ (5).

The objective function is the total fuel cost of conventional generators only in equation

The objective functions of combined cost fuel cost of convectional generators+ DG cost) in equation (6).

$$
F\left(h, g, p, \xi^{\mathrm{int}}\right)=\left\{\sum_{k \in N_{g}}\left(a_{g k}+b_{g k} P_{g k}+c_{g k} P_{g k}\right)+\xi_{k}^{\mathrm{int}}\left(\sum_{k \in N_{P V}}\left(a_{P V k}+b_{P V k} P_{P V k}+c_{P V k} P_{P V k}^{2}\right)\right\}\right.
$$

The line flows from bus- $k$ to bus $-j$ and bus $-j$ to bus- $k$ are given as:

$$
\begin{aligned}
& P_{k j l}=V_{k}^{2} G_{k j}-V_{k} V_{j}\left(G_{k j} \cos \left(\delta_{k}-\delta\right)+B_{k j} \sin \left(\delta_{k}-\delta_{j}\right)\right) \\
& P_{j k l}=V_{j}^{2} G_{k j}-V_{k} V_{j}\left(G_{k j} \cos \left(\delta_{k}-\delta_{j}\right)-B_{k j} \sin \left(\delta_{k}-\delta_{j}\right)\right)
\end{aligned}
$$

A. Equality Constrants:

(a) The presence of distributed generation for all buses, modified equality constraints of real and eactive power flow equations as

$$
\begin{array}{ll}
P_{k}=P_{g k}+\xi_{k}^{\text {int }} * P_{P V}-P_{d k} \forall k=1,2, \ldots N_{b} & \\
Q_{k}=Q_{g k}+\xi_{\text {int }} * Q_{P V k}-Q_{d k} \forall k=1,2, \ldots N_{b} & \\
P_{k}=\sum_{j=1}^{N_{b}} V_{k} V_{j}\left[G_{k j} \cos \left(\delta_{k}-\delta_{j}\right)+B_{k j} \sin \left(\delta_{k}-\delta_{j}\right)\right] & \forall k=1,2, \ldots N_{b} \\
Q_{k}=\sum_{j=1}^{N_{b}} V_{k} V_{j}\left[G_{k j} \sin \left(\delta_{k}-\delta_{j}\right)-B_{k j} \cos \left(\delta_{k}-\delta_{j}\right)\right] & \forall k=1,2, \ldots N_{b}
\end{array}
$$

System real and reactive power balance equations: Define total power generation real and reactive $\left(P_{G T}, Q_{G T}\right)$, total power demand real and reactive $\left(P_{D T}, Q_{D T}\right)$, and total real and reactive power loss $\left(P_{L T}, Q_{L T}\right)$, the system real and reactive power balance equations can be written as:

$$
\begin{aligned}
& P_{G T}-P_{L T}-P_{D T}=0 \\
& Q_{G T}-Q_{L T}-Q_{D T}=0
\end{aligned}
$$

Using general loss formula, total real and reactive power loss can be expressed as [31]:

$$
P_{L T}=\sum_{k=1}^{N_{b}} \sum_{j=1}^{N_{b}}\left[\alpha_{k j}\left(P_{k} P_{j}+Q_{k} Q_{j}\right)+\beta_{k j}\left(Q_{k} P_{j}-Q_{j} P_{k}\right)\right]
$$




$$
\begin{aligned}
& Q_{L T}=\sum_{k=1}^{N_{b}} \sum_{j=1}^{N_{b}}\left[\gamma_{k j}\left(P_{k} P_{j}+Q_{k} Q_{j}\right)+\xi_{k j}\left(Q_{k} P_{j}-Q_{j} P_{k}\right)\right] \\
& \alpha_{k j}=\frac{R_{k j}}{\left|V_{k} V_{j}\right|} \cos \left(\delta_{k}-\delta_{j}\right) \\
& \beta_{k j}=\frac{R_{k j}}{\left|V_{k} V_{j}\right|} \sin \left(\delta_{k}-\delta_{j}\right) \\
& \gamma_{k j}=\frac{X_{k j}}{\left|V_{k} V_{j}\right|} \cos \left(\delta_{k}-\delta_{j}\right) \\
& \xi_{k j}=\frac{X_{k j}}{\left|V_{k} V_{j}\right|} \sin \left(\delta_{k}-\delta_{j}\right)
\end{aligned}
$$

B. Inequality constraints:

(a) Real power generation limit of generators at bus-k $P_{g k}^{\min } \leq P_{g k} \leq P_{g k}^{\max }, k=1,2, \ldots N_{g}$

(b) Reactive power generation limit of generators and other reactive sources at bus- $k$ $Q_{g k}^{\min } \leq Q_{g k} \leq Q_{g k}^{\max }, k=1,2, \ldots N_{q}$

(c) Voltage limit at bus-k $V_{k}^{\min } \leq V_{k} \leq V_{k}^{\max }, k=1,2, \ldots N_{b}$

(d) Phase angle limit at bus-k $\delta_{k}^{\min } \leq \delta_{k} \leq \delta_{k}^{\max }, k=1,2, \ldots N_{b}$

(e) Line flow limits: These Constraints represent maximum power flow in a transmission line and are based on thermal and stability considerations.

$\left|S_{k j}\right| \leq S_{k j}^{\max }$

(f) two new inequality Constraints are added in an OPF model with solar PV based distributed generation

C. Power generation limit: This includes the upper and lower real power generation limit of generators at bus- $k$

(a) Real power generation limit

$P_{P V k}^{\min } \leq P_{P V k} \leq P_{P P_{k}^{\mathrm{m}}}^{\mathrm{m}}, k=1,2, \ldots N_{P V}$

(b) Reactive powergeneration limit

$Q_{P V k}^{\min } \leq Q_{P \backslash k} \leq Q_{P V k}^{\max }, k=1,2, \ldots N_{P V}$

(c) Optimal number of distributed generators: This includes the limit on number of maximum distributed generators in the network.

$\mathcal{N}_{P V}=\sum_{k=1}^{N p v} \xi_{k}^{\mathrm{int}} \leq N_{P V}^{\max }$

\section{Zip Load Model}

The load is modeled as polynomial load [33, 34] as:

$$
\begin{aligned}
& P_{d z}=P_{o}\left(A_{p} V^{2}+B_{p} V+C_{p}\right) \\
& Q_{d z}=Q_{o}\left(A_{q} V^{2}+B_{q} V+C_{q}\right) \\
& \left(A_{p}+B_{p}+C_{p}\right)=\left(A_{q}+B_{q}+C_{q}\right)
\end{aligned}
$$

Where 
$V$ is the p.u. value of the node voltage; $\mathrm{P}_{\mathrm{o}}, \mathrm{Q}_{\mathrm{o}}$ are the real power and reactive power consumed at the specific node under the reference voltage; $A_{p}, A_{q}$ are the parameters for constant impedance (constant $Z$ ) load component; $\mathrm{B}_{\mathrm{p}}, \mathrm{B}_{\mathrm{q}}$ are the parameters for constant current (constant $I$ ) load component; $\quad \mathrm{C}_{\mathrm{p}}, \mathrm{C}_{\mathrm{q}}$ are the parameters for constant power (constant $P$ and $Q$ ) load component.

The values of $A_{p}, A_{q}, B_{p}, B_{q}$ and $C_{p}, C_{q}$ are determined for different load types in distribution systems. Usually experimental or experience values could be used. In the case of zip load, the different possible values of zip load coefficient are taken at each bus.

(a)Without PV-based DG, power balance equations are:

$$
\begin{aligned}
& P_{k}=P_{g k}-P_{d z k} \forall k=1,2, \ldots N_{b} \\
& Q_{k}=Q_{g k}-Q_{d z k} \forall k=1,2, \ldots N_{b}
\end{aligned}
$$

(b) With PV-based DG

With distributed generation the real and reactive power constraints are modified in the presence of zip load as:

$$
\begin{aligned}
& P_{k}=P_{g k}+\xi_{k}^{\text {int }} * P_{P V k}-P_{d z k} \forall k=1,2, \ldots N_{b} \\
& Q_{k}=Q_{g k}+\xi_{k}^{\text {int }} * Q_{P V k}-Q_{d z k} \forall k=1,2, \ldots N_{b}
\end{aligned}
$$

The spot price of real and reactive power has been obtained without and with solar PV in pool based electricity market model. The general form of Lagrange equation can be written as:

$$
L(X, \lambda, \mu)=F(X)+\sum_{k=1}^{m} \lambda_{k} h_{k}(X)+\sum_{\psi_{j=1}}^{n} \mu_{j} g_{i}(X)
$$

At the optimal point, the following conditions must be satisfied as:

$$
\left.\frac{\partial L}{\partial \mu_{k}}\right|_{\underline{x}^{*}, \underline{\lambda}^{*}, \underline{u}^{*}}=0, \quad \mu \geq 0 \text { if } g_{j}(\underline{\underline{x}})=0 \text {, and } \mu_{k}=0 \text { if } g_{j}\left(\underline{x}^{*}\right)<0
$$

Inequality constraints vith be active only if the gradient of the function and constraints are opposite as: $(\nabla F) \nabla g \leq 0 \Rightarrow \mu_{\mathrm{l}} \geq 0$

Where, $X$ are the variables $\lambda_{k}$ are the Lagrange multipliers corresponding to all equality constraints, and $\mu_{\mathrm{k}}$ are the Lagrange multipliers corresponding to inequality constraints. In (38), these Lagrange multipliers have been represented with different symbols for each equality, and inequality constraints for distinction. The Langrangian function for the nodal price determination can be written as a function of $P_{k}$ and $Q_{k}$ as:

$$
\begin{aligned}
& L\left(P_{k}, Q_{k}\right)=\sum_{k \in N_{g}} C_{k}(P)+ \\
& \left.\sum_{k \in N}\left(\lambda_{p}\right) \sum_{j=1}^{R_{k}}-\sum_{j=1}^{N_{k}} V_{k} V_{j}\left[G_{k j} \cos \left(\delta_{k}-\delta_{j}\right)+B_{k j} \sin \left(\delta_{k}-\delta_{j}\right)\right]\right]+\sum_{k=1}^{N_{b}}\left(\lambda_{q k}\right)\left[Q_{k}-\sum_{j=1}^{N_{b}} V_{k} V_{j}\left[G_{k j} \sin \left(\delta_{k}-\delta_{j}\right)-B_{k j} \cos \left(\delta_{k}-\delta_{j}\right)\right]\right] \\
& \text { + } \vartheta_{p l}\left(P_{G T}-P_{D T}-P_{L T}\right)+\vartheta_{q l}\left(Q_{G T}-Q_{D T}-Q_{L T}\right)+\sum_{k=1}^{N_{g}} \mu_{k}^{\max }\left(P_{k}^{\max }-P_{k}\right)+\sum_{k=1}^{N_{g}} \mu_{k}^{\min }\left(P_{k}-P_{k}^{\min }\right)+ \\
& \sum_{k=1}^{N_{q}} \eta_{k}^{\max }\left(Q_{k}^{\max }-Q_{k}\right)+\sum_{k=1}^{N_{q}} \eta_{k}^{\min }\left(Q_{k}-Q_{k}^{\min }\right)+\sum_{k=1}^{N_{b}} \gamma_{k}^{\max }\left(V_{k}^{\max }-V_{k}\right)+\sum_{k=1}^{N_{g}} \gamma_{k}^{\min }\left(V_{k}-V_{k}^{\min }\right)+\sum_{k=1}^{N_{b}} \zeta_{k}^{\max }\left(\delta_{k}^{\max }-\delta_{k}\right) \\
& +\sum_{k=1}^{N_{g}} \zeta_{k}^{\min }\left(\delta_{k}-\delta_{k}^{\min }\right)+\sum_{l=1}^{N_{l}} \psi_{l}\left(S_{l}^{\max }-S_{l}\right)
\end{aligned}
$$


Knowing Lagrangian function, real and reactive power nodal price at any bus- $k$ can be determined as the partial derivative of the Lagrangian function with respect to injected real and reactive power equated to zero as; $\frac{\partial L}{\partial P_{k}}=0, \frac{\partial L}{\partial Q_{k}}=0$.

The marginal price of real and reactive power at each generator node can be obtained as:

$$
\begin{aligned}
& \lambda_{p k}=\frac{\partial\left(\sum_{k \in N_{b}} C_{k}\left(P_{k}\right)\right)}{\partial P_{k}}+\mu_{k}^{\max }-\mu_{k}^{\mathrm{min}}+\vartheta_{p l}\left(1-\frac{\partial P_{L T}}{\partial P_{k}}\right)-\vartheta_{q l}\left(\frac{\partial Q_{L T}}{\partial P_{k}}\right) \\
& \lambda_{q k}=\eta_{k}^{\max }-\eta_{k}^{\min }-\vartheta_{p l}\left(\frac{\partial P_{L T}}{\partial Q_{k}}\right)+\vartheta_{q l}\left(1-\frac{\partial Q_{L T}}{\partial Q_{k}}\right)
\end{aligned}
$$

\section{Results and Discussion}

The proposed approach has been applied to IEEE 24-bus reliâbility test system for an optimal distribution generation location [35]. The result have been obtained for fuel cost, losses, power generation schedule for conventional and distributed generators in the presence of DGs. Five different cases have been considered for analysis. The results have also been obtained with and without presence of DGs for comparison. The maximum number of DGs is defined in the optimization problem for the different cases. The results are also obtained with constant PQ load an Zip load and results also comparison for both load. The results are given in tabular fom in Tables 1 ef.

Results have been obtained considerng different cases with different number of distributed generators.

Case 1: (without PV-based distributed generator)

Case 2: (with one PV-based distributed generator)

Case 3: (With two PV-based distributed generators)

Case 4 :( with three PV-based distributed generators)

Case 5: (With four PV-based distributed generators)

The results obtaned without and with PV-based DG, Table 1 contains the result of the minimization fuel cost including PV-based DG cost with constant load and Table 2 contains the result of the same problem with Zip load. Each table contains the value of fuel cost $D C$ cost, total active and reactive power loss, optimal location and size of DGs, and conventional generation schedule.

\subsection{Results Without and with Solar PV based DG with Constant P, Q and Zip Load Model}

The results have been obtained without and with solar PV based DG considering the cest of cost of both conventional generators and DGs. The results have been obtained for cons ant P,Q load as well as ZIP load model. The results have also been obtained without consideration of cost of solar PV for comparison. 


\subsubsection{Results with Solar PV Cost Function}

Table 1. Results for Minimization of Combined Cost with Constant Load

\begin{tabular}{|c|c|c|c|c|}
\hline & Case1 & Case 2 & Case 3 & Case 4 \\
\hline Fuel cost+ & 14624.93 & 14628.55 & 14631.90 & 14634.70 \\
\hline $\begin{array}{l}\mathrm{DG}(\mathrm{PV}) \\
\operatorname{cost}(\$ / \mathrm{h})\end{array}$ & 36 & 15 & 93 & 96 \\
\hline$D G \operatorname{cost}(\$ / h)$ & 0 & 10.7849 & 25.1488 & 39.5128 \\
\hline PLT(p.u.MW) & 0.4738 & 0.4714 & 0.4725 & 0.4660 \\
\hline QLT(p.u.MVar & -1.2694 & -1.3323 & -1.3873 & -1.4511 \\
\hline $\begin{array}{l}\text { Total } \\
\text { load(p.u.MW) }\end{array}$ & 28.5 & 28.5 & 28.5 & 28.5 \\
\hline $\begin{array}{l}\text { Total } \\
\text { load(p.u.MVar) }\end{array}$ & 5.8 & 5.8 & 5.8 & \\
\hline $\begin{array}{l}\text { Optimal bus } \\
\text { location of } \\
\text { DG(PV) }\end{array}$ & 0 & 3 & & \\
\hline $\begin{array}{c}\text { Total DG(PV) } \\
\text { size(p.u.MW) }\end{array}$ & 0 & & & 858 \\
\hline $\begin{array}{c}\text { Total DG(PV) } \\
\text { size(p.u.MVar) }\end{array}$ & 0 & & & 0.0795 \\
\hline Pg(p.u.MW) & 28.9738 & 28.7552 & 28.4215 & 28.0802 \\
\hline Qg (p.u.MVar) & 4.5306 & 7 & 4.3809 & 4.2694 \\
\hline
\end{tabular}

Table 2. Results for Minimization of Combined Cost with Zip Load

\begin{tabular}{|c|c|c|c|c|}
\hline & Case 1 & Case 2 & Case 3 & Case 4 \\
\hline $\begin{array}{l}\text { Fuel cost+ } \\
\text { DG (PV) } \\
\operatorname{cost}(\$ / h)\end{array}$ & 14620. & 14621.62 & $22^{14625.30}$ & $\begin{array}{c}14628.02 \\
75\end{array}$ \\
\hline$D G \operatorname{cost}(\$ / h)$ & 0 & 10.7849 & 25.1488 & 39.5128 \\
\hline $\operatorname{PLT}($ p.u.MVV) & 0.4988 & 0.4910 & 0.4977 & 0.4939 \\
\hline $\begin{array}{l}\text { QLT (p.u MV } \\
\text { ar) }\end{array}$ & -0.8233 & -0.9005 & -0.9299 & -0.9522 \\
\hline $\begin{array}{l}\text { Total } \\
\text { load(p.u.Mu) }\end{array}$ & 28.2833 & 28.2060 & 28.2084 & 28.1911 \\
\hline $\begin{array}{l}\text { Total } \\
\text { load(p.u.MVar) }\end{array}$ & 5.7558 & 5.7401 & 5.7406 & 5.7371 \\
\hline $\begin{array}{l}\text { Optimal bus } \\
\text { location of } \\
\text { DG(PV) }\end{array}$ & 0 & 3 & 3,10 & $3,4,10$ \\
\hline $\begin{array}{l}\text { Total } \\
\text { DG(PV) } \\
\text { size(p.u.MW) }\end{array}$ & 0 & 0.2162 & 0.5510 & 0.8858 \\
\hline $\begin{array}{l}\text { Total } \\
\text { DG(PV) } \\
\text { size(p.u.MVar) }\end{array}$ & 0 & 0.0308 & 0.0418 & 0.0895 \\
\hline $\mathrm{Pg}$ (p.u.MW) & 28.7821 & 28.4807 & 28.1551 & 27.7992 \\
\hline $\begin{array}{c}\mathrm{Qg} \\
\text { (p.u.MVar) }\end{array}$ & 4.9325 & 4.8088 & 4.7789 & 4.7054 \\
\hline
\end{tabular}


The simulation of combined cost (fuel cost including DG cost) have been determined by solving nonlinear optimization problem. It has been observed the nodal price variations for both real and reactive power at each with and without the presence of distributed generation for the different cases with and without Zip load. The marginal price variations are shown in Figures 1, 2, 5 and 6. In Figures 1 and 5 marginal prices for active power are shown with constant and Zip load respectively. It is observed from Figure 1 and 5 that in the presence of PV-based DGs, the nodal prices have been considerably reduced and the variation of real power prices has also become uniform at all the buses. It is also observed that with Zip load the nodal price are less than with the constant load. With constant load the minimum marginal price occur at bus 7 whereas with zip load minimum marginal price occur at bus 22. With the presence of PV-based DGs, it is observed that two price zones can be represented by single price zone. Thus, the consumers in both the zones will pay similar price. The best results have been obtained in Case5 (with four PV-based DGs). With more penetration of DGs in the network, the improvement in the result is found to be marginal.

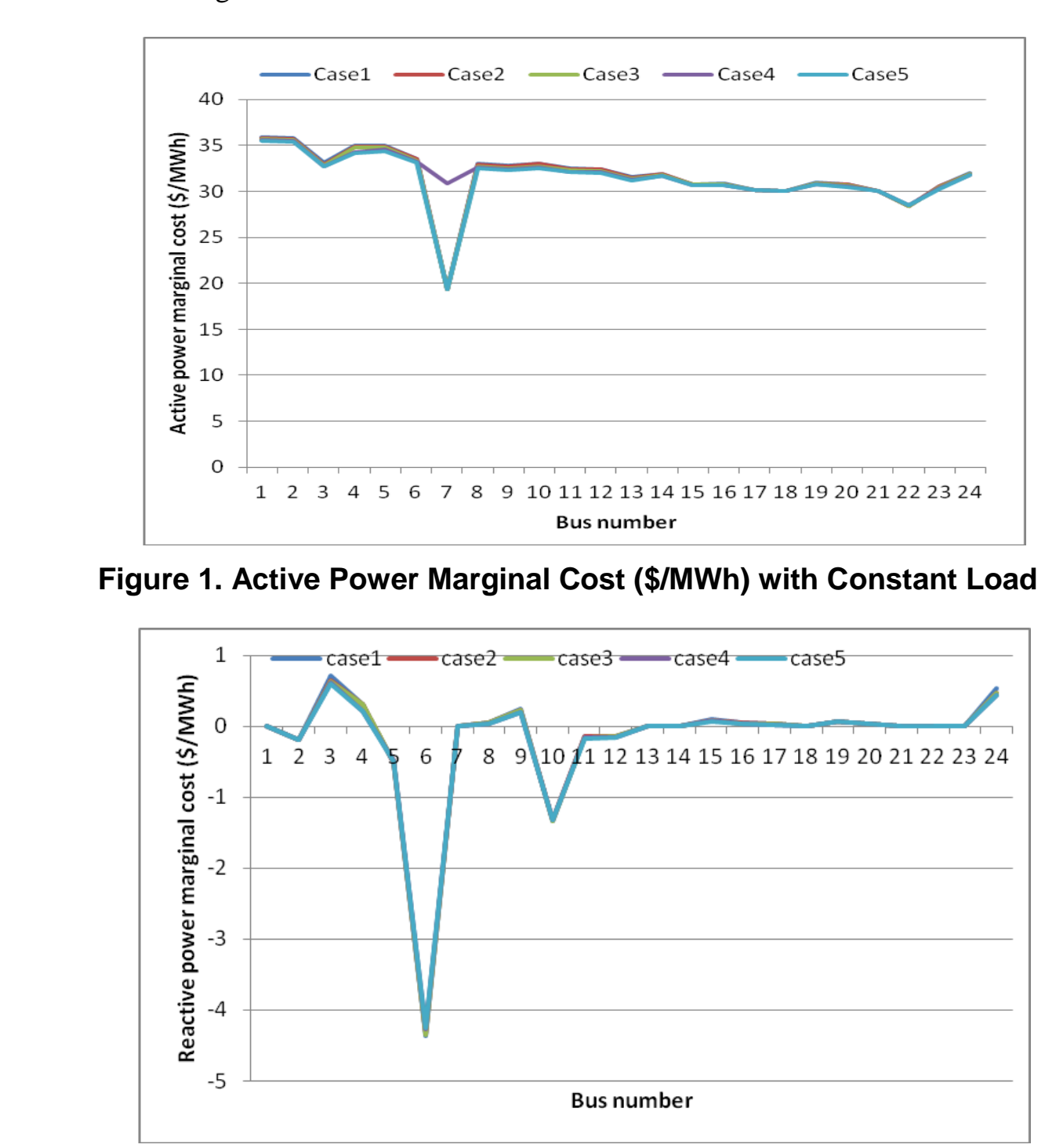

Figure 2. Reactive Power Marginal Cost (\$/MWh) with Constant Load 

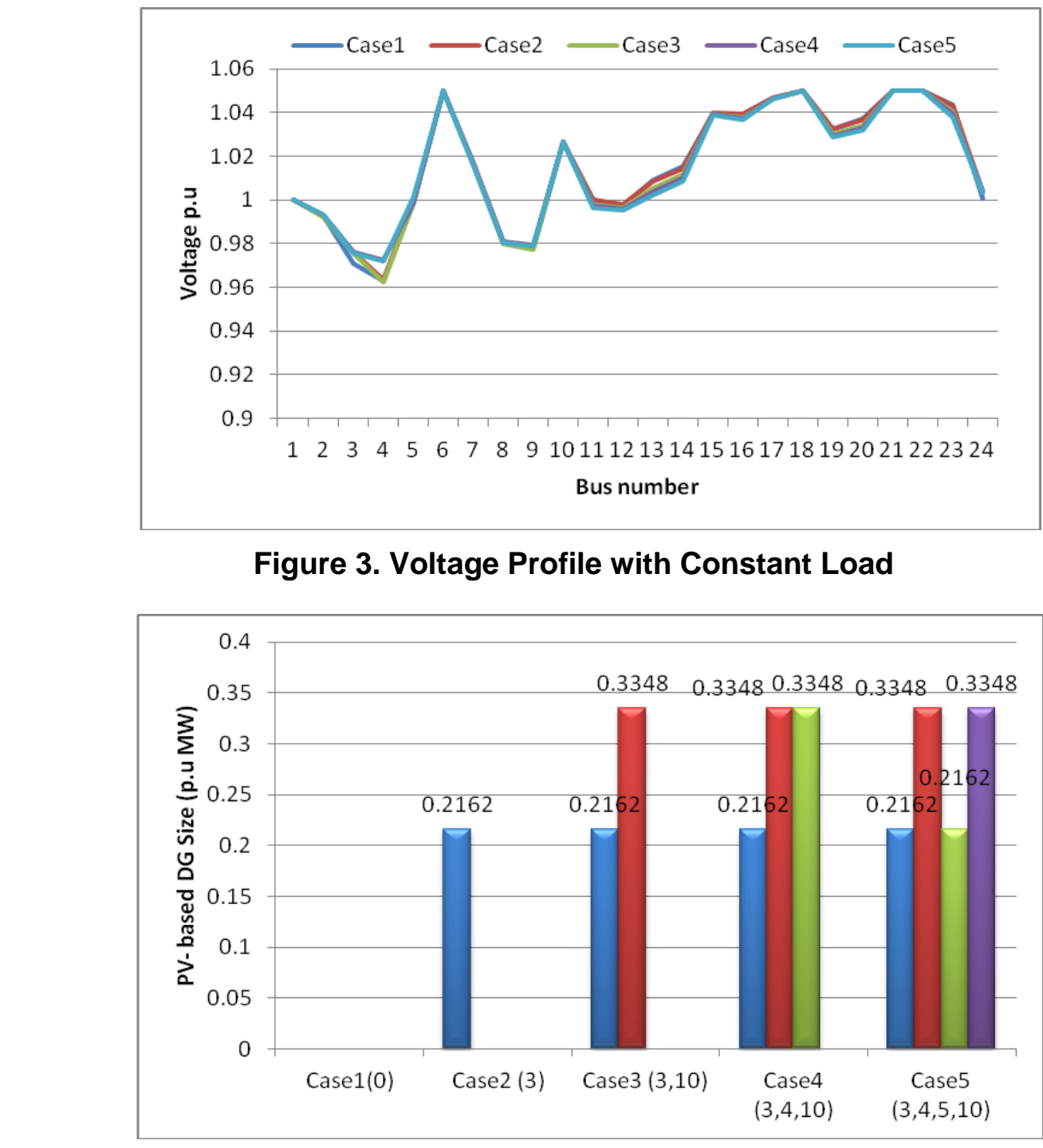

Figure 4. PV-based DG Size (p.u MW) with Constant Load

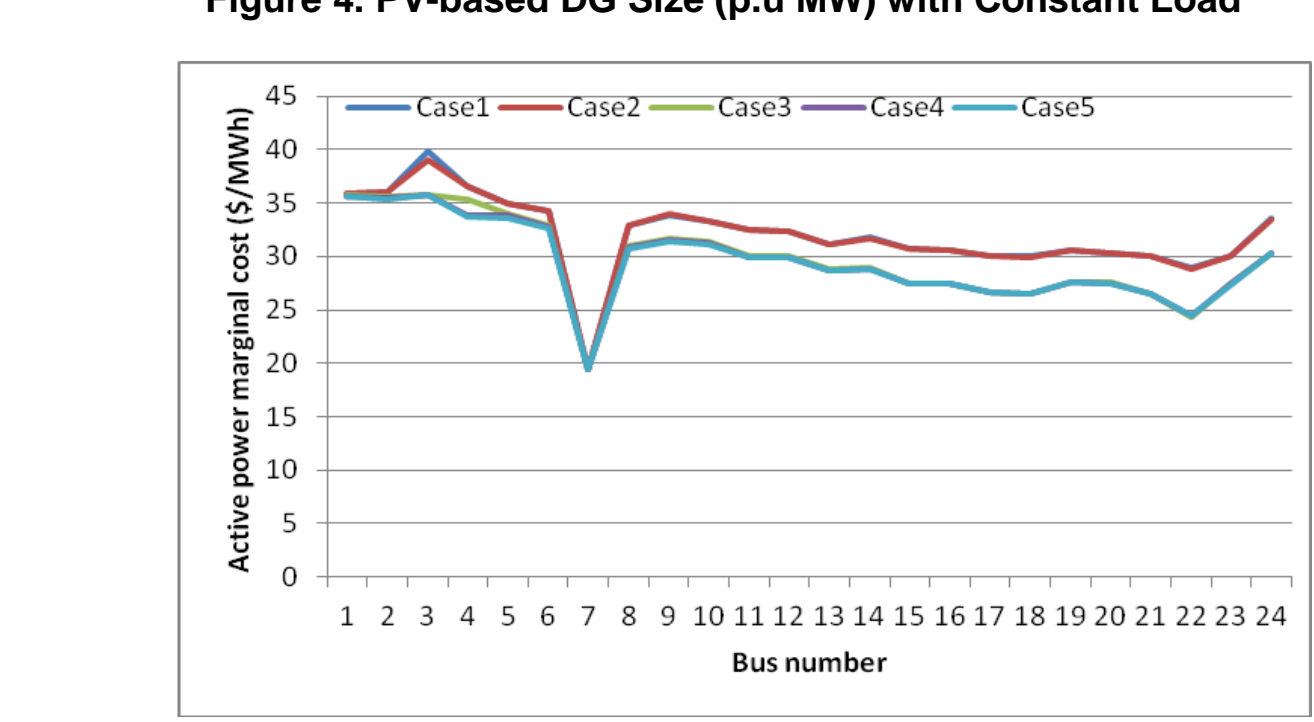

Figure 5. Active Power Marginal Cost (\$/MWh) with Zip Load 


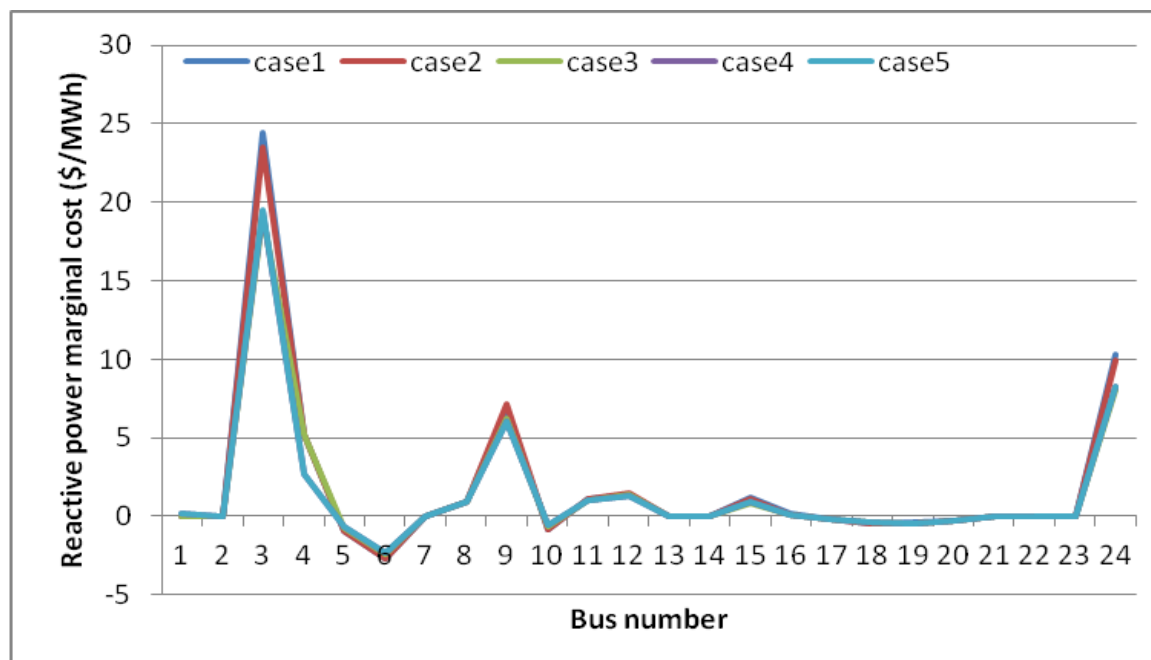

Figure 6. Reactive Power Marginal Cost (\$/MWh) with Zip LOad

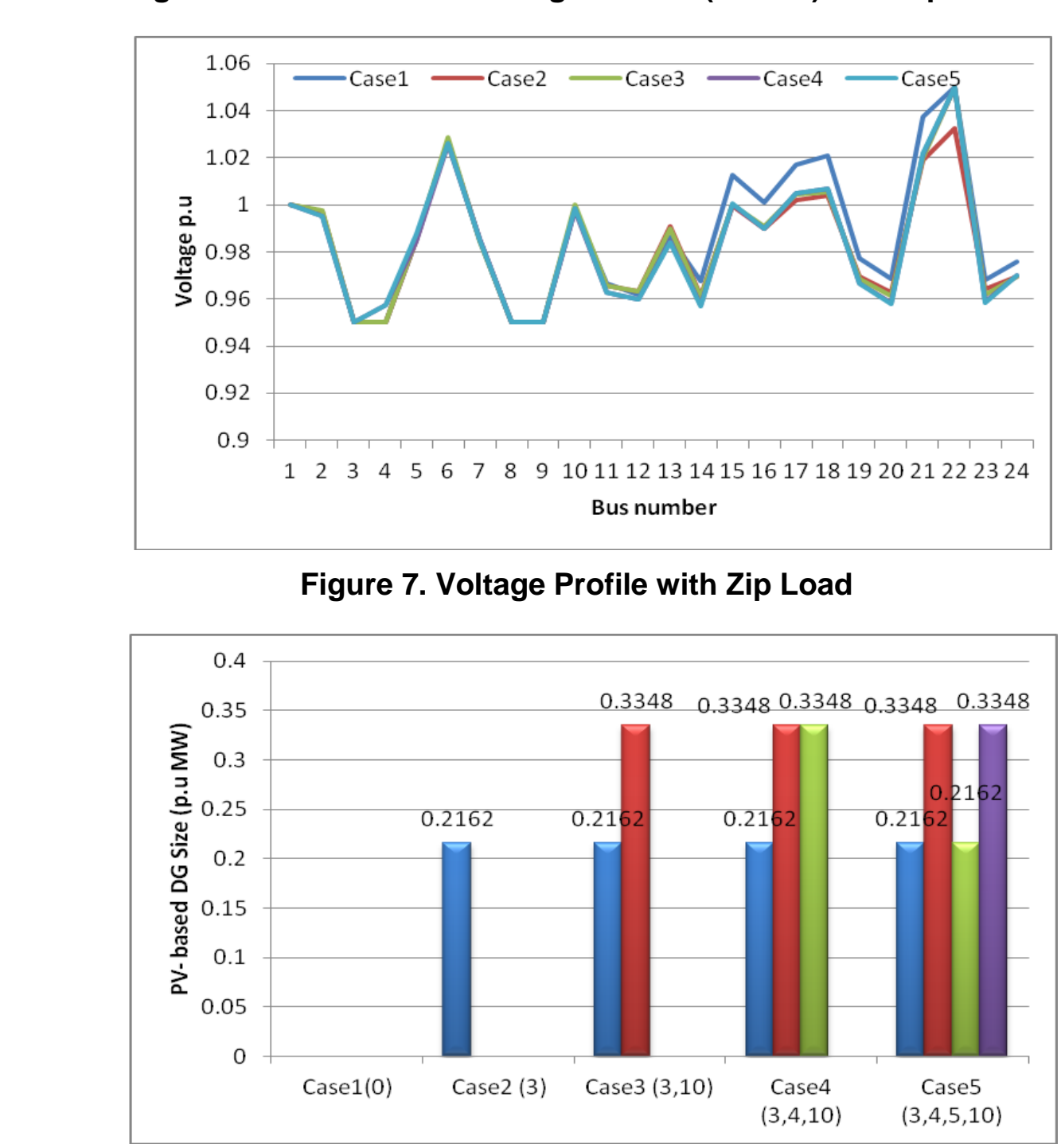

Figure 8. PV-based DG Size (p.u.MW) with Zip Load 
The reactive power price variation with and without PV-based DGs shows in Figure 2 and 6, with constant and Zip load respectively. It is observed from Figure 2 and 6 that the reactive power price is high at nodes 6 with constant load and with Zip load as compared to other buses. Because at these nodes the reactive power absorption is quite high due to the presence of reactor and transformers. Figure 3 and 7 has shown the voltage profile with constant and Zip load model respectively. The number of PV-based DGs increase thus improves the voltage profile of the system. The size of PV-based DGs for optimal location with constant and Zip load model are same its shown in Figure 4 and 8.

\subsubsection{Comparison of Constant and Zip Load with Combine Fuel Cost Case}

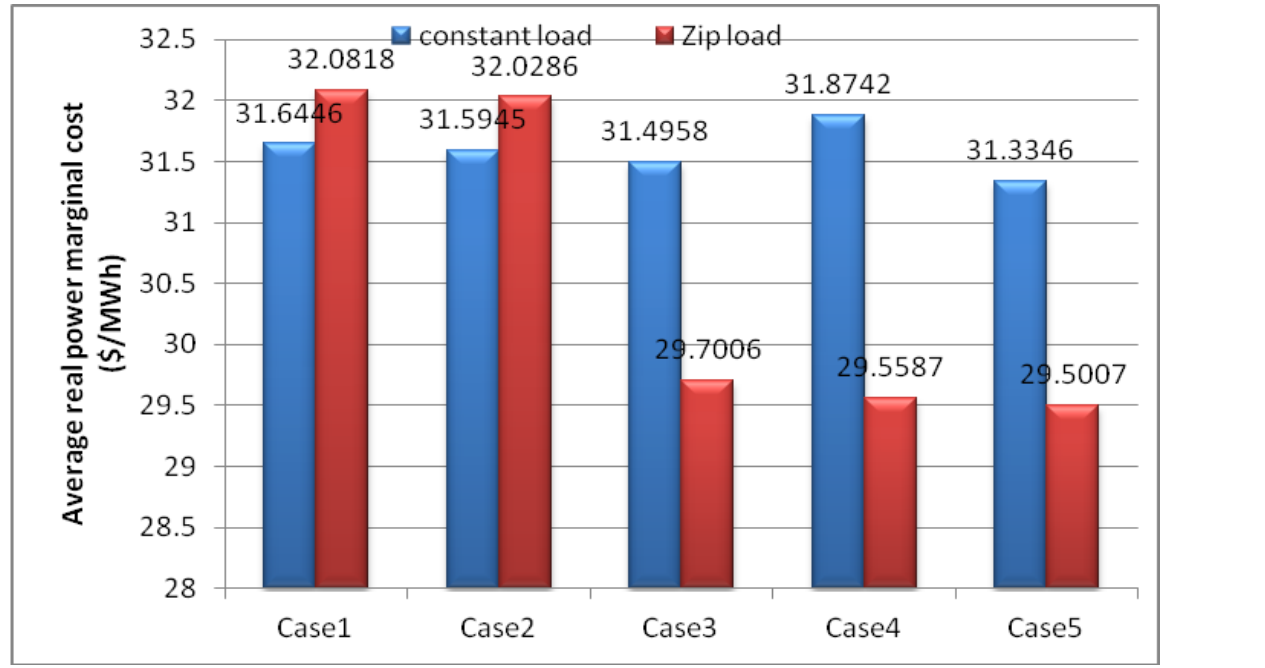

Figure 9. Average Power Marginal Cost (\$/MWh) with Constant and Zip Load

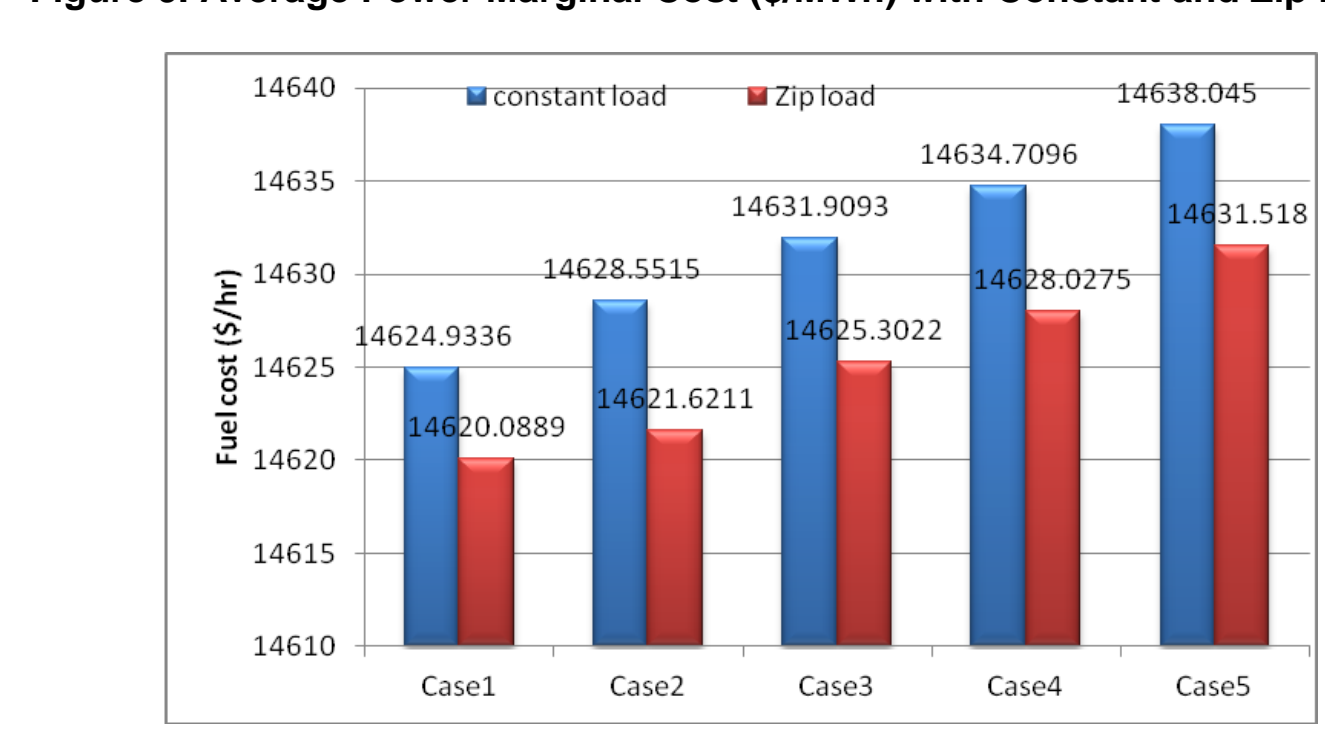

\section{Figure 10. Combine (Convectional + DG) Generator Fuel Cost (\$/hr) with Constant and Zip Load}

The average nodal price variation for each case is shown in the Figure 9 for both load cases. It is observed that nodal price reduces considerably in the presence of PV-based DGs. For Case 1 and Case 2 average real power price with zip load is more than with constant load. Case3, Case4 and Case5 average real power price with constant load is more than Zip load. It is observed that with both load (constant load and Zip load) the Case5 (with four PV-based DGs) average nodal price are minimum. The fuel cost 
increased in the presence of PV-based DGs with constant as well as Zip load is shown in Figure 10. But the marginal nodal price are reduces thus the overall cost are minimize. It can be seen that the saving in fuel cost of conventional generator is more with Zip load than the saving with constant load for all the cases.

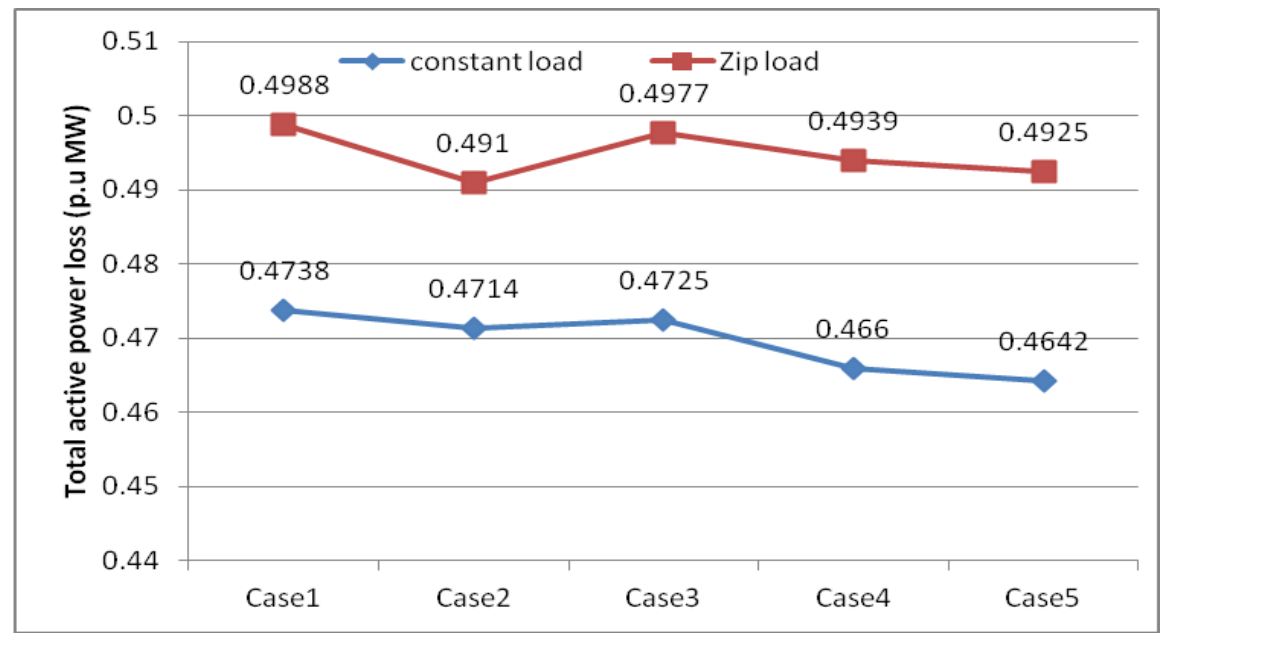

Figure 11. Total Active Power Loss (p.uNW) with Constant and Zip Load

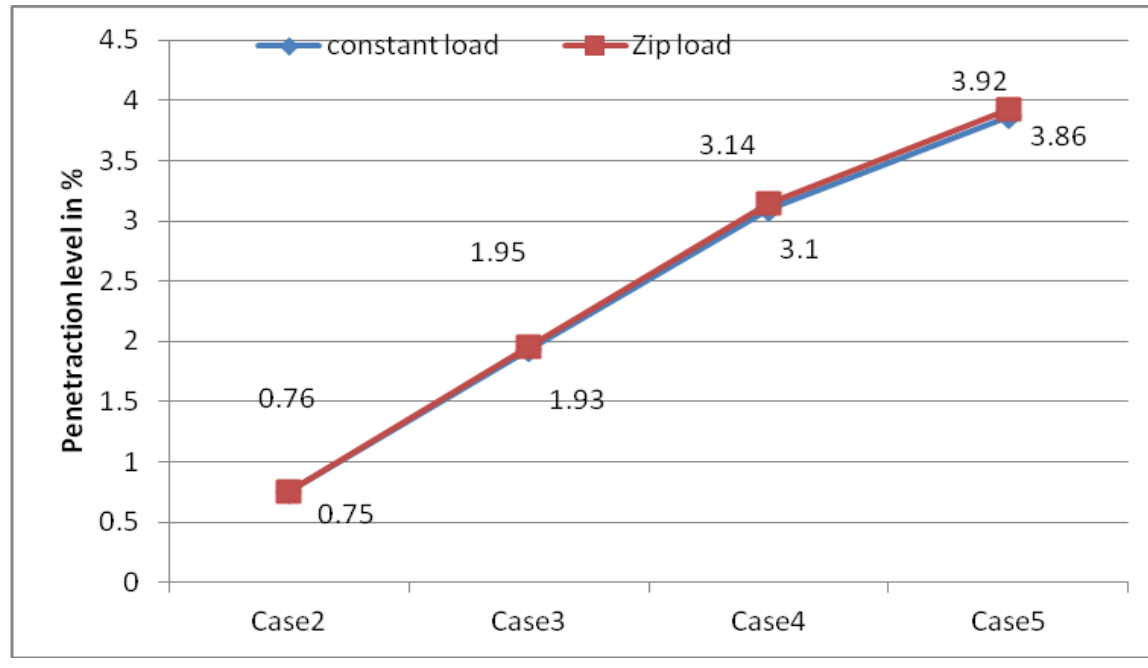

Figure-12. Penetration Level in \% with Constant and Zip Load

The impact on the real power loss in the presence of PV-based DGs is shown in Figure 11. The above data series is given for Zip load and below data series is given for constant load The-system total loss Case1( without PV-based DG ) with constant load are 0.4738 (MW and with Zip load total loss are 0.4988 (MW). In Case2 (with one PV-based DG) the system loss are 0.4714 MW (with constant load) and 0.4910 MW (with Zip load). In Case 3 (with two PV-based DGs) the total real power loss are $0.4725 \mathrm{MW}$ (with constant load) and 0.4977 MW (with Zip load). There is considerable reduction in losses in each case. In case4 (with three PV-based DGs) the total real power loss are $0.4660 \mathrm{MW}$ (with constant load) and 0.4939 MW (with Zip load). In case5 the real power loss are 0.4642 MW (with constant load) and $0.4925 \mathrm{MW}$ (with Zip load). It is observed that losses are considerably reducing with PV-based DG and maximum reduction take place in Case5 (with four PV-based DG) for each load model. With Zip load losses are more as compared to the constant load. 
The distributed generation share for different cases is shown in Figure 12. In Figure 12, above data line has shown the penetration level of Zip load and below data line shown the penetration level of constant load. In all Cases (Case2, Case3, Case4 and Case5) the penetration level is slightly more in case of Zip load than with constant load. It is observed that the saving is more with solar power available in the power system. Optimal number of PV-based DGs required obtaining best results of fuel cost savings is found to be four with both constant as well as Zip load.

\subsubsection{Results with Solar PV DG without Considering Cost of DGs}

We have also obtained the results without and with PV-based DG without considering cost of DGs.Table 3 contains the result of the minimization fuel cost of convectional generator without considering PV-based DG cost with constant load and Table 4 contains the result of the same problem with Zip load. Each table contains the value of fuel cost, DG cost, total active and reactive power loss, optimal location and size of DGs, and conventional generation schedule.

Table 3. Results for Minimization of Fuel Cost of Conventional Generator only with Constant Load

\begin{tabular}{|c|c|c|c|c|}
\hline & Case1 & Case 2 & e & Case 4 \\
\hline $\begin{array}{l}\text { Fuel cost }+ \\
\text { DG (PV) } \\
\operatorname{cost}(\$ / h)\end{array}$ & $36^{14624.93}$ & 14613.30 & $36 \overbrace{}^{14605.80}$ & $28^{14598.67}$ \\
\hline$D G \operatorname{cost}(\$ / h)$ & 0 & 14.3639 & 25.1488 & 35.9337 \\
\hline PLT(p.u.MW) & 0. & 0.4663 & 0.4639 & 0.4618 \\
\hline $\begin{array}{l}\text { Qr) } \\
\text { QLT(p.u.MV }\end{array}$ & & -13390 & -1.3657 & -1.4258 \\
\hline $\begin{array}{l}\text { Total } \\
\text { load(p.u.MW) }\end{array}$ & & & 28.5 & 28.5 \\
\hline $\begin{array}{c}\text { Total } \\
\text { load(p.u.Mvar) }\end{array}$ & 58 & 5.8 & 5.8 & 5.8 \\
\hline $\begin{array}{l}\text { Optimal bus } \\
\text { location of } \\
\text { DG(PV) }\end{array}$ & & 4 & 4,5 & $3,4,5$ \\
\hline $\begin{array}{l}\text { Total } \\
\text { DG(PV) } \\
\text { size(p.u.MiN) }\end{array}$ & 0 & 0.3348 & 0.5510 & 0.7672 \\
\hline $\begin{array}{l}\text { Total } \\
\text { DG(PV) } \\
\text { size(p.u.MVar) }\end{array}$ & 0 & 0.0477 & 0.0487 & 0.0795 \\
\hline Pg(p.u.MW) & $36^{14624.93}$ & $22^{14613.30}$ & $36^{14605.80}$ & $28^{14598.67}$ \\
\hline $\begin{array}{c}\mathrm{Qg} \\
\text { (p.u.MVar) }\end{array}$ & 0 & 14.3639 & 25.1488 & 35.9337 \\
\hline
\end{tabular}


Table 4. Results for Minimization of Fuel Cost of Conventional Generator only with Zip Load

\begin{tabular}{|c|c|c|c|c|}
\hline & Case1 & Case 2 & Case 3 & Case 4 \\
\hline $\begin{array}{l}\text { Fuel cost+ } \\
\text { DG (PV) } \\
\operatorname{cost}(\$ / h)\end{array}$ & $89^{14620.08}$ & $62^{14610.83}$ & $72^{14599.03}$ & $42^{14591.70}$ \\
\hline$D G \operatorname{cost}(\$ / h)$ & 0 & 10.7849 & 25.1488 & 35.9337 \\
\hline PLT(p.u.MW) & 0.4988 & 0.4910 & 0.4905 & 0.4885 \\
\hline $\begin{array}{l}\text { QLT(p.u.MV } \\
\text { ar) }\end{array}$ & -0.8233 & -0.9005 & -0.8993 & -0.9291 \\
\hline $\begin{array}{l}\text { Total } \\
\text { load(p.u.MW) }\end{array}$ & 28.2833 & 28.2060 & 28.1915 & 28.1927 \\
\hline $\begin{array}{l}\text { Total } \\
\text { load(p.u.MVar) }\end{array}$ & 5.7558 & 5.7401 & 5.7 & \\
\hline $\begin{array}{l}\quad \text { Optimal bus } \\
\text { location of } \\
\text { DG(PV) }\end{array}$ & 0 & 3 & & \\
\hline $\begin{array}{l}\text { Total } \\
\text { DG(PV) } \\
\text { size(p.u.MW) }\end{array}$ & 0 & & & .7672 \\
\hline $\begin{array}{c}\text { Total } \\
\text { DG(PV) } \\
\text { size(p.u.MVar) }\end{array}$ & 0 & & & 0.0795 \\
\hline $\mathrm{Pg}$ (p.u.MW) & 28.7821 & & 28.1310 & 27.9140 \\
\hline $\begin{array}{c}\text { Qg } \\
\text { (p.u.MVar) }\end{array}$ & 4.9325 & 4.8088 & 4.7594 & 4.7288 \\
\hline
\end{tabular}

\subsubsection{Comparison of Constant and Zip Load with Convectional Generator Fuel} Cost Case

Figure13 has shown the average nodal price variation at each bus with constant and Zip load for comparison. It is observed that nodal price reduces considerably in the presence of PV-based DGs and become almost uniform. With PV-based DGs, the price of real power is almost uniform in both the zones and customers pay similar price in both the zones. The maximum reduction occurs in marginal price for Case 5 with four PV-based DGs, for constant as well as Zip load. For Case1, Case2, average real nodal price with zip load is môre than with constant load. In Case3, Case4 and Case5 average real nodal price with Zip load is less than with constant load. 


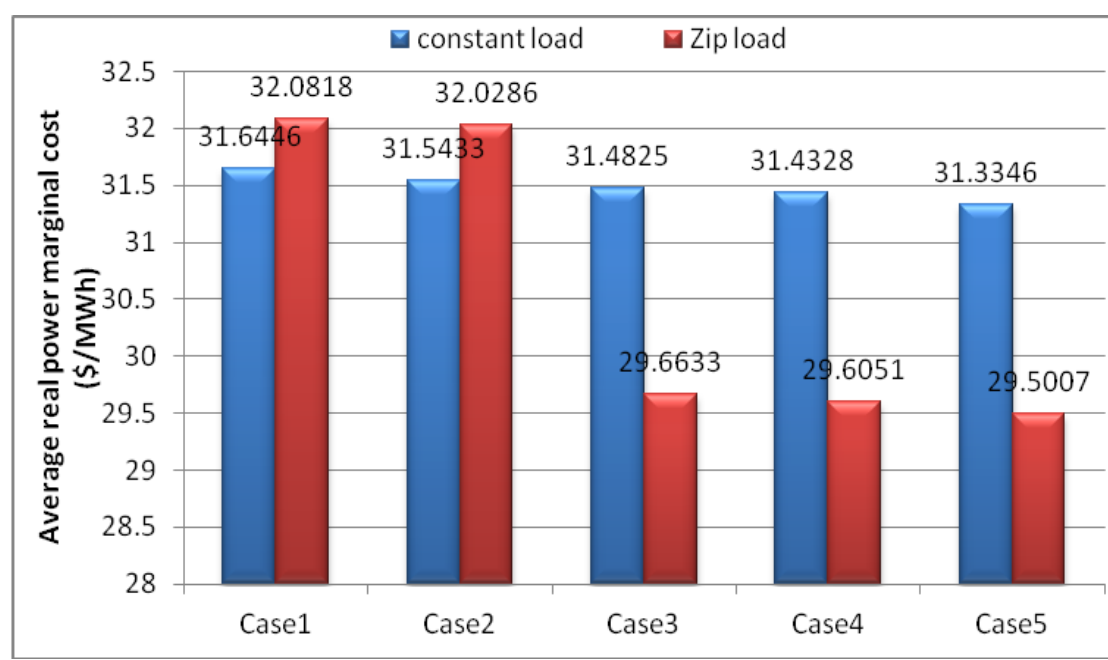

Figure 13. Average Real Power Marginal Cost (\$/MWh) with Constant and Zip Load

The fuel cost reduction in the presence of PV-based DGs wath constant as well as Zip load is shown in Figure 14. It can be seen that the reduction in fuel cost of conventional generator is more with Zip load than the reduction with constant/oad. The fuel cost reduces for all the cases. Minimum fuel cost is found in Case5 (with four PV-based DGs).

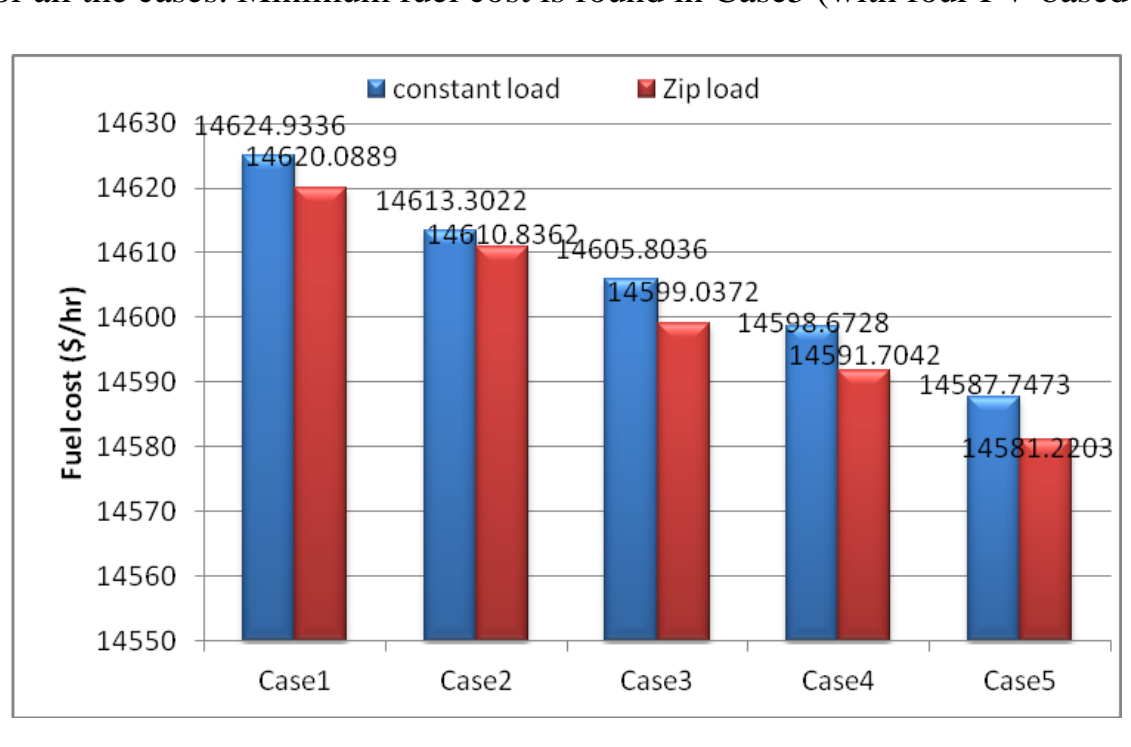

Figure 14 Fuel Cost (\$/h) of Convectional Generator with Constant and Zip

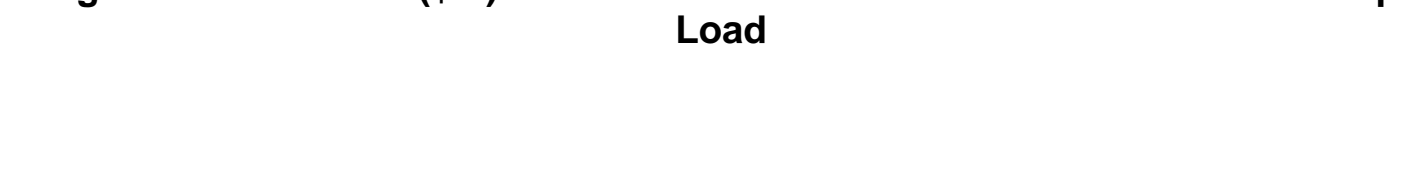




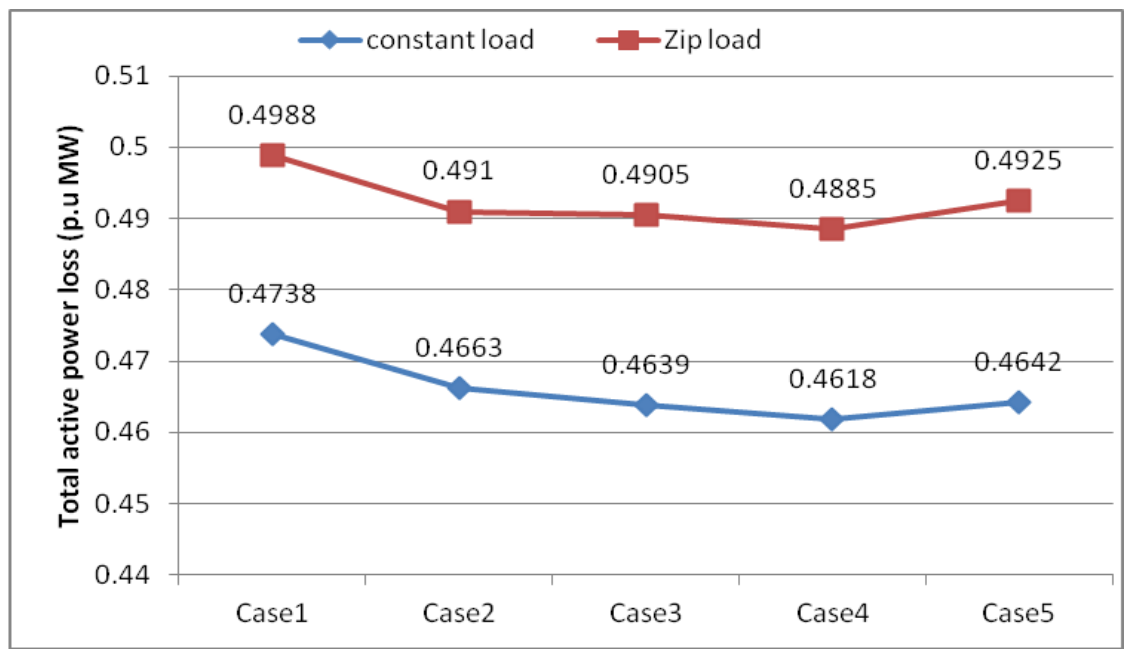

Figure 15. Total Active Power Loss (p.u MW) with Constant and Zip Load

The impact on the real power loss in the presence of PV-based DGs is shown in Figure 15. The above data series are given for Zip load and below data series is given for constant load. The total active power loss Case1 (without PV-based DG) are $0.4738 \mathrm{MW}$ (with constant load) and 0.4988 MW (with zip load).In Case2 (with one PV-based DG) the system loss are $0.4663 \mathrm{MW}$ (with constant load) and $04910 \mathrm{MW}$ (with zip load). In Case3 (with two PV-based DGs) the total eal power loss are 0.4639 MW (with constant load) and $0.4905 \mathrm{MW}$ (with zip load). There is considerable reduction in losses in each case. In Case4 (with three PV-based DGs) the total real power loss are $0.4618 \mathrm{MW}$ (with constant load) and 0.4885 MW (wip zip load). In Case5 (with four PV-based DGs) the real power loss are $0.4642 \mathrm{MW}$ (with constantload) and $0.4925 \mathrm{MW}$ (with zip load). It is observed that losses are considerably reduced with PV-based DG and maximum reduction take place in Case4 (with chree PV-based DG) for each load model. With zip load Losses are more as compared to the constant load.

The ratio of DG size to the total demand in the system is called the penetration level of the DGs. The distributed generation share for different cases has been shown in Figure16. The penetration level is slightly more in case of Zip load than with constant load. It is observed that the fuel cost saving is higher with more penetrations level of PV-based DGs. Optimal number of PV-based DGs required obtaining best results of fuel cost minimization is found to be four with both constant as well as zip load. 


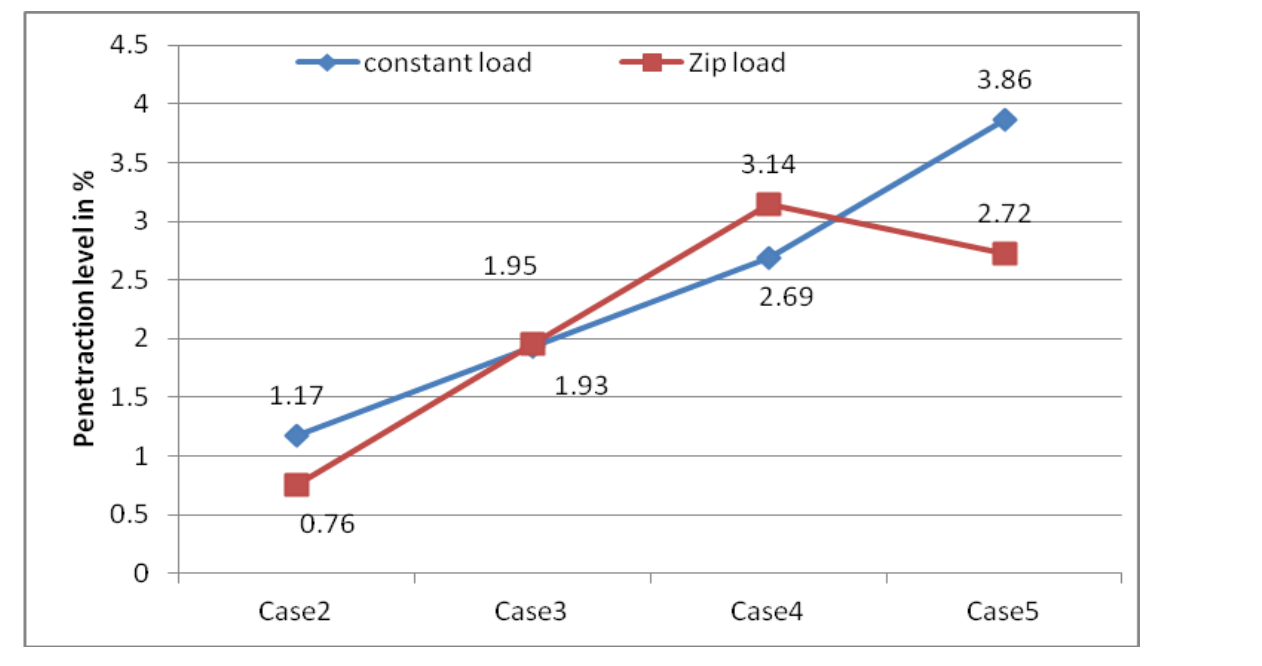

Figure 16. Penetration Level in \% with Constant and Zip Load

\section{Conclusions}

In this paper, analysis has been carried out with solar PV system in the network. Different cases have been considered with solar PV. The cost function of solar PV system has been considered in the objective function. The mixed integer non-linear programming approach has been utilized for optimal location and optimal number of distributed generators. It is observed that with PV-basedDGs, thermarginal nodal prices of both real and reactive power reduce at each bus. Lod model has considerable impact on the prices, losses, and voltage profile. With increase in penetration level of DGs, the losses reduce considerably. The fuel cost reduces vith. The minimum fuel cost in Case5 with four DG of conventional generator $14588.9549 \$ / \mathrm{hr}$ (witb constant load) and $14582.0349 \$ / \mathrm{hr}$ (with zip load).

\section{References}

[1] R.C. Dugan and S. K. Price, "Issues for distributed generations in the US", in Proc. IEEE PES, Winter Meeting v01. (2002), pp. 121-126.

[2] G.A. Estevez, R.P. Behnke R.T. Avila and L.S. Vargas, "A competitive market integration model for distributed generation" (IEEE Transactions on Power Systems, vol. 22, no. 4, (2007).

[3] T. Ackermann, G. Andersson and L. Soder, "Distributed generation: a definition", Electric Power System Research, vol.57, (2001), pp. 195-204.

[4] W. El-Khattan and M.M.A. Salama, "Distributed generation technologies, definitions and benefits", Electric Power System Research, vol. 71, (2004), pp. 119-128.

[5] P. Chiradeja and R. Ramkumar, "An approach to quantify for technical benefits of distributed generation", IEEE Transactions on Energy Conversion, vol. 19, no. 4, (Dec. 2004), pp. 764-773.

[6] M. Don elaar, "A survey of solutions and options for integration of distributed generation in electricity supply systems," Journal of Energy and Environment, vol. 15, no. 2, (2004), pp. 323-332.

17] -.A.P. Lopes, N. Hatziargyriou, J. Mutale, P. Djapic and N. Jenkins, "Integrating distributed generation nto electric power systems: A review of drivers, challenges and opportunities", Electric Power System Research, vol. 77, (2007), pp. 1189-1203.

[8] W. Rosehart and E. Nowicki, "Optimal placement of distributed generation", in Proc. 14 $4^{\text {th }}$ PSC conference, Sevilla, (2002), pp. 1-5.

[9] S. Porkar, A. Abbaspour-Tehrani Fard and S. Saadate, "An approach to distribution system planning by implementing distributed generation in a deregulated electricity market", in Proc. Power System Large Engg. System Conf., (2007), pp. 90-95.

[10] K. Nara, Y. Hayashi, K. Lkeda and T. Ashizawa, "Application of tabu search to optimal placement of distribution generators", IEEE power engineering society winter meeting, (2001), pp.918-923.

[11] N.S. Rau and Y-H. Wan, "Optimum location of resource in distributed planning", IEEE Trans Power Syts, vol.4, (1994), pp.2014-2020. 
[12] M. Mohammadi and M. Nafar, "Optimal placement of multi types DG as independent private sector under pool/hybrid power market using GA-based Tabu search method", International Journal of Electrical Power \& Energy Systems, vol.51, (2013), pp.43-53.

[13] C. Wang and MH. Nshrir, "Analysis approach for optimal placement of distributed generation source in power system”, IEEE Trans Power Syst, vol.19, no.4, (2004),pp.2068-2076.

[14] M.H. Moradi and M. Abedini, "A combination of genetic algorithm and particle swarm optimization for optimal DG location and sizing in distribution systems", International Journal of Electrical Power \& Energy Systems, vol.34, no.1, (2012), pp.66-74.

[15] K. Kim, K. Song, S. Joo, Y. Lee and J. Kim, "Multi-objective distributed generation placement using fuzzy goal programming with genetic algorithm", Euro Trans Electric Power, vol.18, (2008), pp.217230.

[16] DT. Le, M.A. Kashem, M. Negnevitsky and G. Ledwich, "Optimal distributed generation parameters for reducing losses with economic consideration", IEEE general meeting, vol.24, no.28, (2007), pp.1-8.

[17] S. Ghosh, S.P. Ghoshal and S. Ghosh, "Optimal sizing and placement of distributed generation in a network system", Int J Electr Power Syst, vol.32, (2010), pp.849-856.

[18] S. Porkar, P. Poure, A. Abbaspur-Tehrani-fard and S. Saadate, "A noval optimal distribution system planning framework implementing distributed generation in a deregulated electrical market", Int I Electr: Power Syst, vol.60,(2010), pp.828-837.

[19] W. Lingfeng and C. Singh, "Reliability-constrained optimum placement of reclosers and distributed generators in distribution networks using an ant colony system algorithm", IEEE Trans Syst Man Cybern C: Appl Rev, vol.38, no.6, (2008), pp.757-64.

[20] S.G.B. Dasan, S.S. Ramalakshmi and R.P.K. Devi, "Optimal siting and sizing of hybrid distributed generation using EP", In: Proceedings of the international conference on power systenis, ICPS, (2009), pp.1-6.

[21] F. Rotaru, G. Chicco, G. Grigoras and G. Cartina, "Two-stage distributed generation optimal sizing with clustering-based node selection", Int J Electr Power Energy Syst, vol.40,(2012), pp.120-9.

[22] R.W. Chang, N. Mithulananthan and T.K. Saha, "Novel mixed-integer method to optimize distributed generation mix in primary distribution systems", In 21 AUPEC. B isbane, Australia, (2011), pp.25-28.

[23] R. Viral and D.K. Khatod, "Optimal planning of distributed generation systems in distribution system: a review”, Renew Sustain Energy Rev, vol. 16, (2012), pp.5146-65.

[24] A.K Singh and S.K. Parida, "Allocation of distributed generan using proposed DMSP approach based on utility and customers aspects under deregulated environment", Electrical power and Energy system, vol. 68,(2015), pp.159-169.

[25] L.D. Arya, A. Koshti and S.C. Choube, "Distribated generation planning using differential evolution accounting voltage stability consideration", Int JUlectric Power Energy Syst, vol.42, no.1,(2012), pp.196-207.

[26] F. Ugranli and E. Karaepe, "Multiple-distributed generation planning under load uncertainty and different penetration levels, Int J Electric Power Energy Syst, vol.46, (2013), pp.132-44.

[27] M. Govarthan and R. Roy, "Economic analysis of unit commitment with distributed energy resource", Electric power and Energy system, vol.71, (2015), pp.1-14.

[28] J.A. Garcia Martin and A.J. Mena Gil, "Optimal distributed generation location and size using a modified teaching-learning based optimization algorithm", International Journal of Electrical Power \& Energy Systems, vol.50-(2013), pp.65-75.

[29] A. Kumar, M. Kumar and K.S. Sandhu, "Optimal DFIG Location and Impact of Load Model in Pool Electricity Market, Proceedings of the 2014 International Conference on Power Systems, Energy, Environment (PSEE 2014), Interlaken, Switzerland, (2014), pp.149-156.

[30] M. Kumar, KS. Sandhu and A. Kumar, "Wind speed variation impact on transmission loss reduction in electricity market", Procedia computer science, vol.70, (2015), pp.526-537.

[31] Y.M. Atwa, E.F. Saadany, M.M.A. Salama and R. Seethapathy, "Optimal renewable resources mix for distribution system energy loss minimization”, IEEE Trans. Power Syst, vol. 25, no.1, (2012), pp. 360370.

[32] E. Crisostomi, M. Liu, M. Raugi and R. Shorten, "Plig and Play Distributed Algorithms for Optimized ower generation in a micro grid", IEEE Transaction on smart grid, vol.5, no.4, (2014), pp.2145-2154.

[33] M.M.A. Salama and A.Y. Chikhani, "A simplified network approach to the VAR control problem for radial distribution system", IEEE Trans. Power Delivery, vol.8, no.3, (1993).

[34] M.M.A Salama, "Lecture Notes of ECE760, Distribution System Engineering”, University of Waterloo, (2000).

[35] IEEE Reliability Test System, A report prepared by the Reliability Test System Task Force of the Applications of Probability Methods Subcommittee, IEEE Trans. on Power Apparatus and Systems, vol. PAS-98, (1979), pp. 2047-2054. 